\title{
Lactobacillus maltaromicus, a New Species Producing a Malty Aroma ${ }^{1}$
}

\author{
A. MILlER III, M. E. MORGAN, and L. M. LIBBEY \\ Department of Food Science and Technology \\ Oregon State University, Corvallis, Oregon 97331
}

\begin{abstract}
The characterization of several isolates of a new lactic acid bacterium which produces a malty aroma is presented. Strains MX5R, MX5S, 674S, and 628S were asporogenous, catalase-negative, gram-positive, aciduric rods of varying length which did not reduce nitrate. The above strains also formed $\mathbf{L}(+)$-lactic acid, produced 0.3 to $0.4 \%$ acidity in sterile milk, and grew at $7,15,25$, and 32 $\mathrm{C}$ but not at $45 \mathrm{C}$. In addition, all strains produced limited amounts of $\mathrm{CO}_{2}$ from gluconate, did not produce $\mathrm{CO}_{2}$ from glucose, required riboflavin and folic acid but not thiamine for growth, and demonstrated fructose-1,6-diphosphate aldolase (EC 4.1.2.13) activity. The guanine plus cytosine contents of deoxyribonucleic acid (DNA) extracted from representative strains MX5R and MX5S were 36.0 and $36.1 \mathrm{~mol} \%$, respectively. All isolates produced an extracellular nuclease which hydrolyzed ribonucleic acid as well as DNA. Like Streptococcus lactis subsp. maltigenes, all strains produced 2-methylpropanal, 2-methylpropanol, 3-methylbutanal, and 3-methylbutanol in skim milk and Trypticase soy broth. The characteristic malty aroma is most likely due to the production of the above aldehydes. On the basis of the data presented, the malty strains were placed in a new species, Lactobacillus maltaromicus, in the subgenus Streptobacterium. Strain MX5 (ATCO 27865) was designated the type strain of L. maltaromicus.
\end{abstract}

Several early investigations $(8,12,34,35)$ described a lactic acid bacterium which produced a malt-like flavor and aroma in milk and butter. Since the organism involved was closely related to Streptococcus lactis but could be differentiated from it by the ability to produce the characteristic flavor and aroma, it was designated $S$. lactis subsp. maltigenes. More recent studies provide additional justification for this designation (20).

The neutral volatiles from milk cultures of $S$. lactis subsp. maltigenes consist of a number of aldehydes formed from certain amino acids via enzymatic transamination of $\alpha$-ketoglutaric acid and decarboxylation of resultant keto acids $(14,15,39)$. The presence of corresponding alcohols is the result of aldehyde reduction (24). Although the malty aroma and flavor produced by $S$. lactis subsp. maltigenes in milk is due primarily to the production of 3-methylbutanal, Sheldon et al. (36) suggested that a collective expression of several volatile components may be involved.

\footnotetext{
${ }^{1}$ Technical paper no. 3357, Oregon Agricultural Experiment Station, Oregon State University. Corvallis, Ore. 97331.
}

In addition to $S$. lactis subsp. maltigenes, other bacteria have been associated with the malty character. Tracy and Ramsey (38) reported that malty aroma could be caused by a pathogenic micrococcus of the Staphylococcus aureus type and that the flavor could be enhanced when a strain of Bacillus subtilis was also present. Leesmont (13) reported that the streptococcus flora producing malty flavor in starters and in butter was dominated by $S$. diacetilactis subsp. maltigenes, whereas the defect in other dairy products was mainly due to $S$. lactis subsp. maltigenes. Overby (29) also associated malty aroma and flavor with $S$. diacetilactis. Other organisms that have been implicated with the malty characteristic are $S$. faecalis (5), $S$. faecium, and $S$. bovis (1).

This investigation is concerned with the morphologic, physiologic, and molecular characterization of several strains of Lactobacillus isolated from milk samples having developed a distinct malty aroma. These strains are generally phenotypically related to $L$. casei, but the significantly different guanine plus cystosine (GC) contents $(\mathrm{mol} \%)$ of their deoxyribonucleic acids (DNA) strongly suggest that they represent a new species of Lactobacillus. 


\section{MATERIALS AND METHODS}

Organisms and media. Three samples of producers' milk criticized as possessing a malty flavor were submitted to our laboratory for microbiological examination and evaluation. A portion $(0.01 \mathrm{ml})$ of each sample was streaked on Trypticase soy agar (BBL) and the plates were incubated at $25 \mathrm{C}$ for 5 days. Preliminary microscopic examination of a number of colonies revealed filamentous, rod-shaped bacteria but no typical lactic acid streptococci. Selected colonies, designated as rough or smooth, were transferred to Trypticase soy broth (TSB) or MRS broth (3) and incubated at $30 \mathrm{C}$. All cultures developed a strong malty aroma within 24 to $48 \mathrm{~h}$. Frequent purity checks were conducted, and selected isolates, designated MX5R, MX5S, 674S, 628R, and $628 \mathrm{~S}$, were maintained in sterile skim milk at $-12 \mathrm{C}$. The malty character was stable upon repeated transfer over a period of 6 years.

Fermentation of carbohydrates. Fermentation tests were conducted on a variety of carbohydrates by using the modified selective medium of Rogosa et al. (33) and purple broth base (Difco). Carbohydrates were added to the above basal media at concentrations of 2 and $1 \%$, respectively. Arabinose, xylose, mannose, galactose, fructose, maltose, and rhamnose were sterilized by filtration and then added to the basal media. The inocula were prepared by making at least two preliminary transfers in TSB. When substantial growth was apparent, the cells were washed two times with sterile, distilled water. All tubes were inoculated with $0.05 \mathrm{ml}$ of the concentrated cell preparation, incubated at 30 to $32 \mathrm{C}$, and observed daily for distinct color changes over a period of 2 weeks. The $\mathrm{pH}$ of the contents of each tube was then determined. Appropriate controls, consisting of the basal medium without added carbohydrate, were also inoculated with the test organism and examined as described above.

Gas $\left(\mathrm{CO}_{2}\right)$ production. Tomato juice broth (Difco), supplemented with 1,2 , and $5 \%$ glucose, and a modification of the basal medium of Rogosa (9) were used to detect the production of $\mathrm{CO}_{2}$ from glucose and gluconate, respectively. In the preparation of the latter medium, tryptone was substituted for tryptose, potassium gluconate $(4 \%)$ was added, ammonium citrate was deleted, and the $\mathrm{pH}$ was adjusted to 5.5. Sterile Vaseline or paraffin was layered over the surface of the inoculated media, and $\mathrm{CO}_{2}$ production was observed directly in the tubes between 4 and 14 days of incubation at 30 to $32 \mathrm{C}$.

Titratable acidity. Acidity in sterile skim milk was determined as described by Rogosa et al. (33) after incubation at $30 \mathrm{C}$ for 14 days. All values were corrected for the acidity of an uninoculated control.

Temperature growth limits. All isolates were examined for ability to grow in TSB at controlled temperatures ranging from 7 to $45 \mathrm{C}$. Inoculated medium was incubated at the desired temperature and examined for turbidity after 14 days.

Optical rotation of lactic acid. Total lactic acid in cell-free supernatants prepared from TSB cultures was determined essentially by the method of Mattsson (18) as reported by Daly et al. (2). The amount of lactic acid was determined colorimetrically after the addition of an aqueous solution of $2 \% \mathrm{FeCl}_{3} \cdot 6 \mathrm{H}_{2} \mathrm{O}$. The optical density at $425 \mathrm{~nm}$ was recorded within 15 min with a Bausch \& Lomb Spectronic 20 spectrophotometer. Data obtained from the enzymatic determination of $\mathrm{L}(+)$-lactic acid was used to confirm the total lactic acid results $(2,18)$. The optical density at $340 \mathrm{~nm}$ was determined with a Beckman DU spectrophotometer, and the amount of L(+)-lactic acid was obtained from a standard curve. The control organisms, $L$. casei and $L$. plantarum, produced $L(+)$ and DL-lactic acid, respectively. Nicotinamide adenine dinucleotide (grade III) and lactic dehydrogenase were obtained from Sigma Chemical Co.

Aldolase assay. Fructose-1,6-diphosphate aldolase (EC 4.1.2.13) was assayed at $340 \mathrm{~nm}$ essentially as described by Rogosa (personal communication). The reaction mixture, total volume $2 \mathrm{ml}$, contained the following: $1 \mathrm{ml}$ of $0.05 \mathrm{M}$ tris(hydroxymethyl)aminomethane-hydrochloride, $\mathrm{pH} 7.5$ containing 0.02 $\mathrm{M}$ potassium acetate and $0.05 \mathrm{M} \beta$-mercaptoethanol); $0.2 \mathrm{ml}$ of $0.1 \mathrm{mM}$ NADH (Calbiochem, San Diego, Calif.); $0.02 \mathrm{ml}$ of crude cell-free extract; $0.02 \mathrm{ml}$ of a $1: 10$ dilution of $\alpha$-glycerophosphate dehydrogenasetriosephosphate isomerase (rabbit muscle; Calbiochem, San Diego, Calif.); $0.2 \mathrm{ml}$ of fructose-1,6-diphosphate $(0.02 \mathrm{M})$; and $0.5 \mathrm{ml}$ of distilled water. All reaction mixtures were equilibrated at $32 \mathrm{C}$ before the addition of fructose-1,6-diphosphate.

Nutritional characteristics. Microinoculum broth (Difco) and riboflavin, thiamine, and folic acid assay media (Difco) were prepared essentially as described in the Difco Manual (4). All tubes, including a duplicate set containing riboflavin $(0.3 \mu \mathrm{g} / 10 \mathrm{ml})$, thiamine $(0.05 \mu \mathrm{g} / 10 \mathrm{ml})$, and folic acid $(0.01 \mu \mathrm{g} / 10 \mathrm{ml})$, were inoculated with the test culture, incubated at 30 to 32 $\mathrm{C}$, and observed daily for growth response or turbidity change.

Morphology and additional biochemical tests. Morphologic characteristics were determined on 48-h-old cultures in TSB and thermoacidurans broth (Difco). Catalase production and nitrate reduction were determined by standard procedures previously described (37). In addition, all strains were examined for their ability to grow in TSB at various concentrations, 0.1 to $0.7 \%$, of Teepol (anionic detergent comprising alkyl sulfates).

DNA base composition. Thermal denaturation $\left(T_{m}\right)$ values of purified DNA, extracted as described by Marmur (16), were determined with a Gilford (model 2000) automatic recording spectrophotometer. Escherichia coli DNA (Nutritional Biochemicals Corp., Cleveland, Ohio) was used as a control and reference in all determinations. Mol\% GC was calculated according to the linear relation of Marmur and Doty (17). Normal distribution curves were constructed from absorbance-temperature denaturation profiles by plotting the change in slope per degree increase in temperature $(\Delta \tan \Theta / C)$ against temperature $(12)$.

Extracellular nuclease assay. Extracellular nuclease activity was detected by using deoxyribonuclease test agar (Difco) plates and MRS agar (3) supplemented with either herring sperm DNA (2 g/liter) or Torula ribonucleic acid (RNA; $2 \mathrm{~g} /$ liter), obtained from Calbiochem, Los Angeles, Calif. The latter medium 
was modified by omitting Tween 80 and reducing the beef extract and glucose concentrations to 0.3 and $0.5 \%$, respectively. In addition, tryptone was substituted for proteose peptone. All plates were heavily inoculated with the test organisms and incubated at several temperatures ranging from 15 to $32 \mathrm{C}$ for 3 days. Extracellular hydrolytic activity was then assayed by lightly flooding the plates with $1 \mathrm{~N} \mathrm{HCl} \mathrm{(10).}$

Gas-liquid chromatography. Volatile compounds from cultures that developed a strong malty aroma in milk and TSB were separated and identified on columns ( $3.7 \mathrm{~m}$ by $3 \mathrm{~mm}$ outer diameter) containing acid-base-washed Celite 545 (60 to 80 mesh) coated with either $20 \%$ 1,2,3-tris(2-cyanoethoxy)propane or 1,2,4-butanetriol by using a gas-entrainment, oncolumn trapping procedure (23). The columns, installed in a Varian Aerograph (series 1200) gas chromatograph, were operated isothermally at $60 \mathrm{C}$ with a nitrogen gas flow rate of $30 \mathrm{ml} / \mathrm{min}$, and the detector and injection port temperatures were 210 and $190 \mathrm{C}$, respectively.

Mass spectral analysis. An F \& M model 810 gas chromatograph was used in conjunction with an Atlas CH-4 mass spectrometer for all spectral analyses of separated compounds. The operating conditions were: filament emission, $12 \mu \mathrm{A}$; electron voltage, $70 \mathrm{eV}$; accelerating voltage, $3.0 \mathrm{kV}$; analyzer pressure, $2 \times$ $10^{-6}$ torr; multiplier voltage, $1.6 \mathrm{kV}$; and scanning speed, $2.5 \mathrm{~s}$ for $\mathrm{m} / \mathrm{e} 25$ to 250 . A microvolume switching valve (Carle Instruments Inc., Fullerton, Calif.) was installed between the mass spectrometer and gas chromatograph to prevent air from entering the ion source during sample transfer.

\section{RESULTS}

Morphology and physiology. Morphologic characteristics of strains MX5R, MX5S, and $628 \mathrm{~S}$ are illustrated in Fig. 1. All isolates were asporogenous, gram-positive rods of varying length which became gram negative with increasing age. Whether cells appeared as long filaments or shorter rods appeared to be related to the medium in which they were grown and not to the rough or smooth character of the
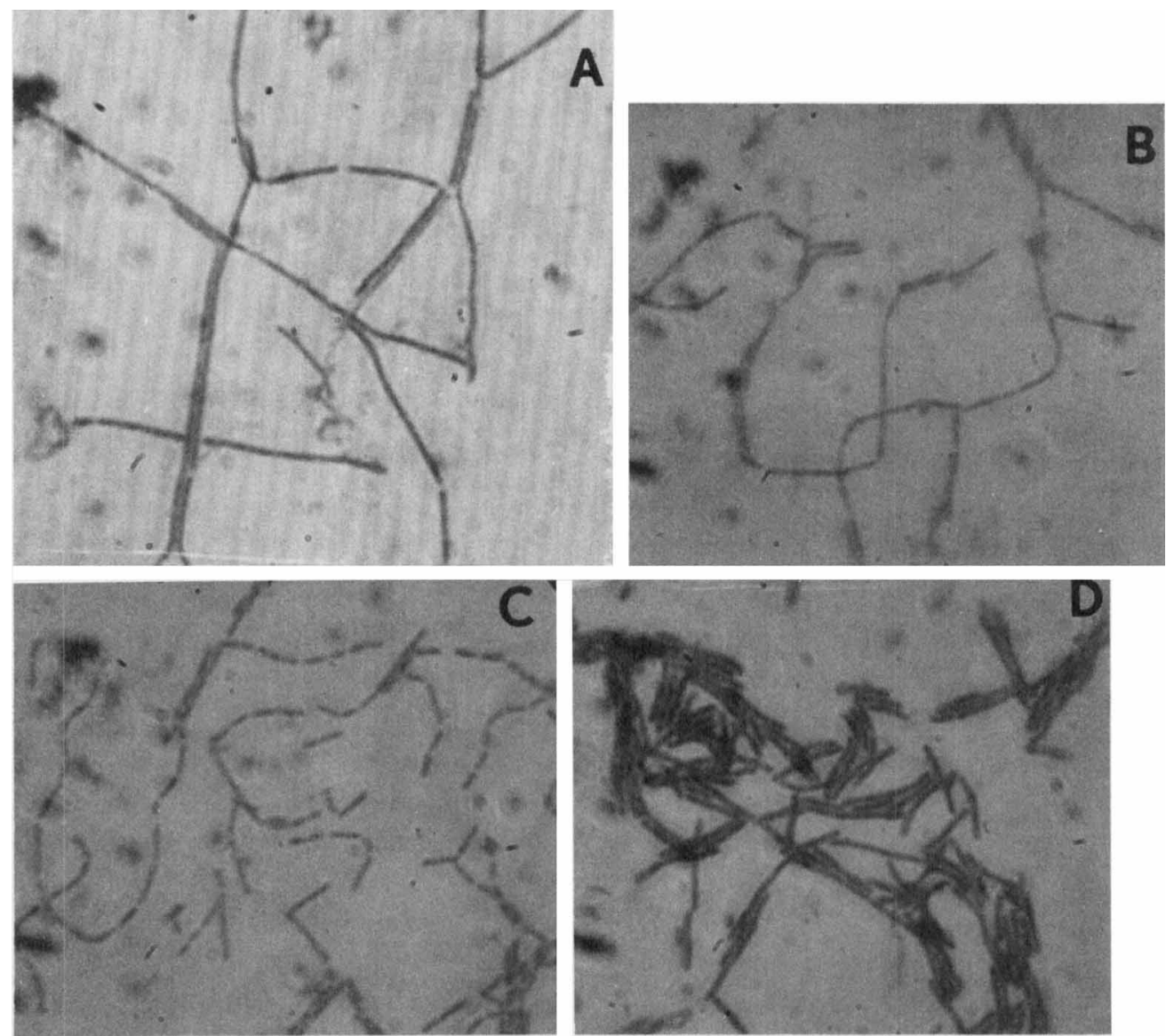

FIG. 1. Photomicrographs of 48-h-old TSB cultures of (A) MXSR, (B) MX5S, (C) 628S, and (D) 48-h-old culture of $628 \mathrm{~S}$ in thermoacidurans medium. 
colonial form. Colonies of the smooth isolates were white, convex, smooth, and opalescent, with edges changing with age from entire to slightly fimbriate. Colonies of the rough isolates were markedly fimbriate with a course, ground-glass appearance. Some physiologic characteristics of these isolates and $674 \mathrm{~S}$ are given in Table 1. Strains MX5R and MX5S produced $0.4 \%$ acidity and $674 \mathrm{~S}$ and $628 \mathrm{~S}$ produced $0.3 \%$ acidity in sterile skim milk after 14 days of incubation at $30 \mathrm{C}$. All isolates were catalase negative, did not reduce nitrate, grew at $7,15,25$, and $32 \mathrm{C}$ but not at $45 \mathrm{C}$, and developed in TSB with concentrations of Teepol ranging from 0.1 to $0.7 \%$. Although growth was evident at the higher concentrations (0.5 to $0.7 \%$ ), development was more pronounced at the lower levels. In addition, all strains produced limited amounts of $\mathrm{CO}_{2}$ from gluconate, did not produce $\mathrm{CO}_{2}$ from glucose $(1,2$, and 5\%), demonstrated fructose-1, 6-diphosphate aldolase activity, and produced $\mathrm{L}(+)$-lactic acid $(1.35$ to $1.65 \mathrm{mg} / \mathrm{ml})$ from available glucose $(2.5 \mathrm{mg} / \mathrm{ml})$. The control organisms, L. plantarum $\mathrm{P} 5$ and $17-5$ and typical strains of $L$. casei subsp. casei, formed DL- and L(+)-lactic acid, respectively, did not produce gas from glucose, produced substantial amounts of $\mathrm{CO}_{2}$ from gluconate, and were also aldolase positive.

TABLE 1. Physiologic characteristics of strains $M X 5 R, M X 5 S, 674 S$, and $628 S$

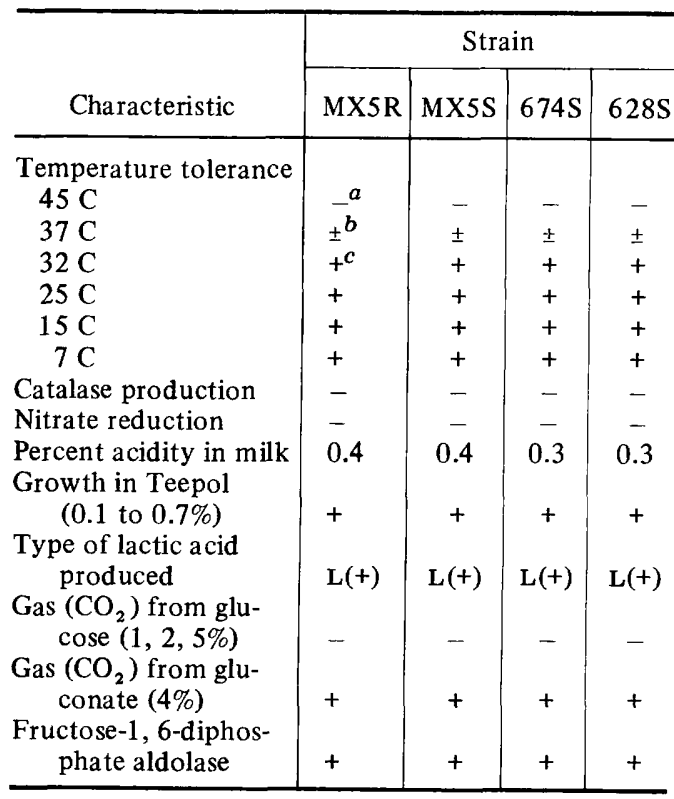

${ }^{a}$ No growth or negative reaction.

b Limited growth.

${ }^{c}$ Substantial growth or positive reaction.
Fermentation characteristics. Preliminary fermentation reactions in the selective medium (pH 5.9) of Rogosa et al. (33) were slow and, in many cases, weak. Nevertheless, the results substantiated the aciduric nature of the isolates. Strains MX5S, 674S, and 628S fermented glucose, amygdalin, salicin, cellobiose, mannose, fructose, lactose, sucrose, and trehalose. MX5R utilized glucose but was only capable of weakly fermenting mannose and fructose. Stronger reactions, possibly due to the greater activity of the inocula, were observed in purple broth base (Difco) supplemented with a variety of carbohydrates (Table 2). The fermentation characteristics were similar for all isolates; however, melibiose was not utilized to any appreciable extent by strains $674 \mathrm{~S}$ and $628 \mathrm{~S}$. Although MX5R and MX5S fermented melibiose within 3 days, the reactions were considered weak when compared with reactions for known strains of $L$. plantarum. All strains fermented $D(-)$-ribose, but none utilized erythritol, adonitol, dulcitol, raffinose, inositol, xylose, arabinose, or rhamnose. These results are generally consistent with the known fer-

TABLE 2. Fermentation characteristics of strains $M X 5 R, M X 5 S, 674 S$, and $628 S$

\begin{tabular}{|c|c|c|c|c|}
\hline \multirow[b]{2}{*}{ Substrate $^{a}$} & \multicolumn{4}{|c|}{ Strain } \\
\hline & MX5R & MX5S & $674 \mathrm{~S}$ & 628 \\
\hline Ribose & $4.7^{b}$ & 4.9 & $4.6^{c}$ & $4.6^{c}$ \\
\hline Glucose . . & $4.6^{+1 c}$ & $4.4^{+1}$ & $4.5^{+1}$ & $4.5^{+1}$ \\
\hline Fructose .... & $4.9^{+1}$ & $4.6^{+1}$ & $4.6^{+1}$ & $4.5^{+1}$ \\
\hline Galactose ... & $5.1^{+1}$ & $5.1^{+1}$ & $5.0^{+1}$ & $5.1^{+1}$ \\
\hline Mannose ... & $4.9^{+1}$ & $4.6^{+1}$ & $4.6^{+1}$ & $4.6^{+1}$ \\
\hline Maltose .... & $4.8^{+1}$ & $4.6^{+1}$ & $4.7^{+1}$ & $4.8^{+1}$ \\
\hline Lacto & $4.9^{+1}$ & $4.7^{+1}$ & $4.7^{+1}$ & $4.7^{+1}$ \\
\hline Sucr & $4.7^{+1}$ & $4.6^{+1}$ & $4.6^{+1}$ & $4.6^{+1}$ \\
\hline Cellobiose. & $4.9^{+1}$ & $4.6^{+1}$ & $4.6^{+1}$ & $4.6^{+1}$ \\
\hline Melezitose & $5.4^{+1}$ & $5.2^{+2}$ & $5.2^{+2}$ & $5.7^{+3}$ \\
\hline Trehalose. & $4.9^{+1}$ & $4.9^{+1}$ & $4.9^{+1}$ & $4.9^{+1}$ \\
\hline Melibiose & $5.9^{+3}$ & $5.9^{+3}$ & $6.0^{-}$ & $6.1^{-}$ \\
\hline Manni & $5.3^{+1}$ & $4.9^{+1}$ & $5.1^{+2}$ & $5.0^{+2}$ \\
\hline Sor & $5.4^{+1}$ & $5.4^{+1}$ & $5.4^{+2}$ & $5.4^{+3}$ \\
\hline$\alpha$-Methyl-D-glucoside . & $5.4^{+1}$ & $5.3^{+1}$ & $5.2^{+1}$ & $5.3^{+2}$ \\
\hline$\alpha$-Methyl-D-mannoside & $5.0^{+1}$ & $4.9^{+2}$ & $4.9^{+2}$ & $4.9^{+2}$ \\
\hline Salicin .......... & $4.8^{+1}$ & $4.6^{+1}$ & $4.6^{+1}$ & $4.6^{+1}$ \\
\hline Amygdalin .. & $4.7^{+1}$ & $4.6^{+1}$ & $4.6^{+1}$ & $4.6^{+1}$ \\
\hline Control $^{d} \ldots$ & 6.8 & 6.7 & 6.6 & 6.6 \\
\hline
\end{tabular}

${ }^{a}$ Basal medium, purple broth. Erythritol, adonitol, dulcitol, inositol, raffinose, xylose, arabinose, and rhamnose were not fermented by any of the isolates.

- Number indicates pH at 7 days; the day a distinct color change was observed was not recorded.

${ }^{c}$ Number indicates $\mathrm{pH}$ at 14 days; superscript signifies day a distinct color change was observed.

$d$ Inoculated basal broth containing no added carbohydrates. 
mentation characteristics of $L$. casei subsp. casei.

Growth factor requirements. The malty isolates and the strains of $L$. casei and $L$. plantarum studied did not require thiamine for growth (Table 3). Riboflavin and folic acid were essential and stimulatory for all cultures except those of $L$. plantarum. With respect to these observations, the malty isolates appeared to be more closely related to $L$. case $i$ than to $L$. plantarum.

DNA base composition. DNA extracted from representative malty isolates, MX5R and MX5S, gave monophasic absorbance-temperature denaturation profiles, and the compositional distribution of DNA molecules was relatively narrow and unimodal. The absorbance-temperature denaturation profile and normal distribution curve for MX5S DNA are illustrated in Fig. 2. The $T_{m}$ values for MX5R and MX5S, 84.0 and $84.1 \mathrm{C}$, respectively, are an average of three determinations and were reproducible within 0.2 C. Corresponding GC contents calculated for MX5R and MX5S were 36.0 and 36.1 mol\%, respectively.

Extracellular nuclease. The extracellular nuclease activity of MX5R, MX5S, 674S, and $628 \mathrm{~S}$ on deoxyribonuclease test agar (Difco) is shown in Fig. 3. All isolates were capable of depolymerizing RNA, as well as DNA, and zones of hydrolysis ranged from 2 to $5 \mathrm{~mm}$ in diameter from the colony edge.

Gas-liquid chromatography. Typical chromatograms of the volatiles produced in skim milk and TSB by strain $674 \mathrm{R}$ are illustrated in Fig. 4. Diethyl ether was considered a persistent contaminant in the atmosphere in which the samples were prepared and analyzed. Peak 8, chromatogram (A), consisted primarily of 2-methylpropanol with a trace of diacetyl. The

TABLE 3. Growth factor requirements of Lactobacillus casei, $L$. plantarum, and several malty isolates

\begin{tabular}{l|c|c|c}
\hline \multicolumn{1}{c|}{ Strain } & Thiamine & Riboflavin & Folic acid \\
\hline MX5R & $-a$ & $+\mathrm{S}^{b}$ & $+\mathrm{VS}$ \\
MX5S & - & $+\mathrm{S}$ & $+\mathrm{VS}$ \\
$628 \mathrm{R}$ & - & $+\mathrm{S}$ & $+\mathrm{VS}$ \\
$628 \mathrm{~S}$ & - & $+\mathrm{S}$ & $+\mathrm{VS}$ \\
$674 \mathrm{R}$ & - & $+\mathrm{S}$ & $+\mathrm{VS}$ \\
674S & - & $+\mathrm{S}$ & $+\mathrm{VS}$ \\
L. casei 780 & & & \\
and C17 & - & $+\mathrm{VS}$ & $+\mathrm{VS}$ \\
L. plantarum & & & \\
17-5 & - & - & - \\
\hline
\end{tabular}

${ }^{a}$ No requirement.

$b$ Requirement and stimulatory.

${ }^{c}$ Requirement and very stimulatory.

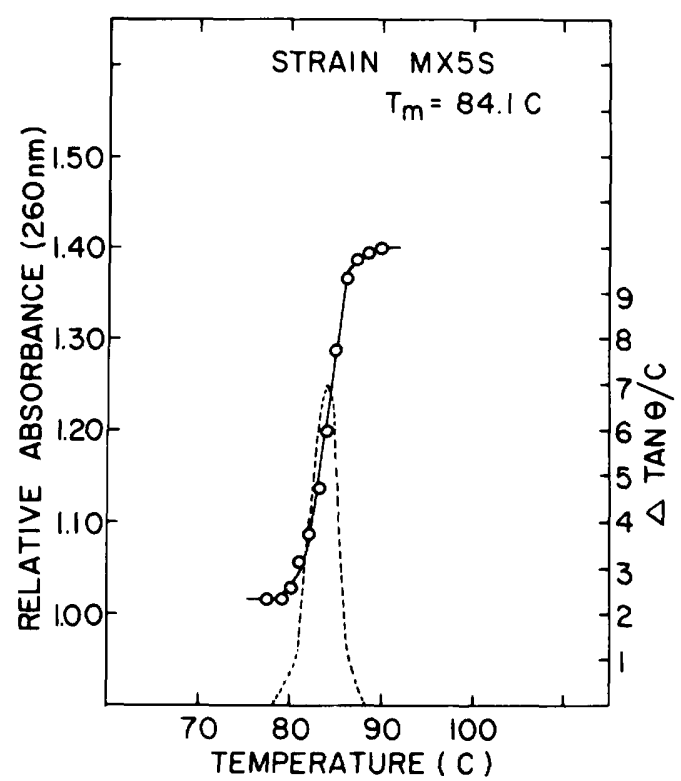

FIG. 2. Absorbance-temperature denaturation profile and normal distribution curve for MXSS DNA.

same peak in chromatogram (B), however, comprised a greater amount of diacetyl in relation to 2-methylpropanol. Major peaks corresponding to ethanol and 3-methylbutanol were also detected in the volatiles entrained from a TSB culture of $674 \mathrm{R}$ using the 1,2,4-butanetriol column. All identifications were made by comparisons of mass spectra with reference spectra and relative retention times of authentic compounds. Although similar chromatographic patterns were observed for strains $674 \mathrm{~S}, \mathrm{MX} 5 \mathrm{R}, \mathrm{MX} 5 \mathrm{~S}, 628 \mathrm{R}$, and $628 \mathrm{~S}$, minor differences in intensity were observed. The data presented correlated well with results previously reported for $S$. lactis subsp. maltigenes (24). L. casei $\mathrm{C} 17$ and 316 and L. plantarum 17-5 did not produce any of the characteristic aldehydes or corresponding alcohols generally associated with the malty character (24).

\section{DISCUSSION}

All strains isolated and characterized in this investigation were similar with respect to morphologic and physiologic characteristics. They were homofermentative, gram-positive, catalase-negative, aciduric rods of varying length which were not capable of nitrate reduction. On the basis of these general characteristics, the isolates were tentatively placed in the genus Lactobacillus.

Recognized species of lactobacilli were previously placed in three groups on the basis of 


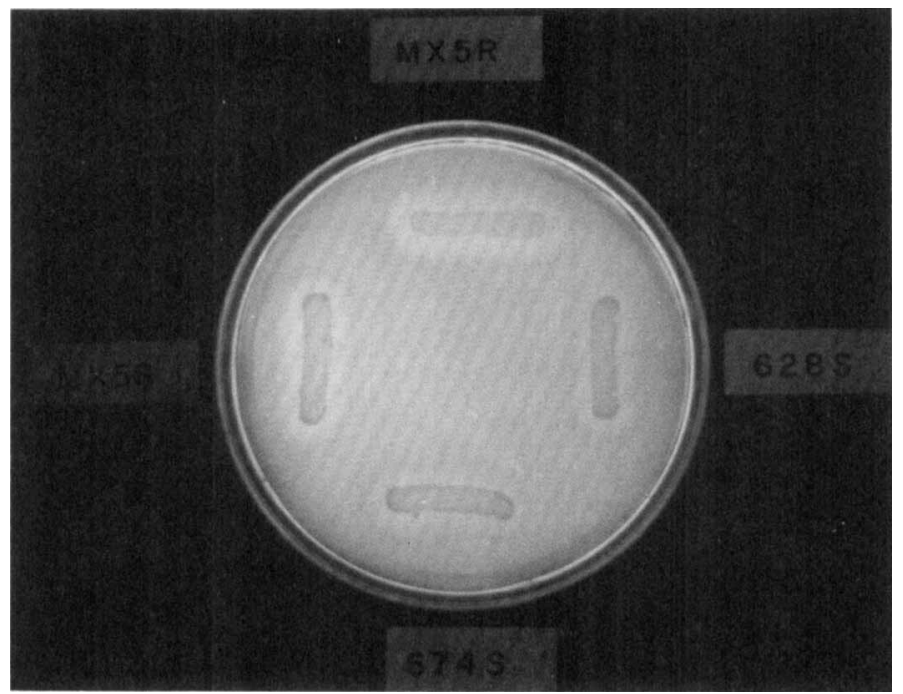

FIG. 3. Extracellular nuclease activity of $M X 5 R, M X 5 S, 674 S$, and $628 S$.

DNA base composition (22). Group I included species with a GC content between 32.4 and $38.3 \mathrm{~mol} \%$, group II included species with a GC content between 42.7 and $48.0 \mathrm{~mol} \%$, and group III included species with a GC content between 49.0 and $51.9 \mathrm{~mol} \%$. Although similarities were observed, groups I, II, and III did not correspond entirely with the three subgenera recognized in traditional classifications $(28,32)$. The GC contents for MX5R and MX5S, 36.0 and $36.1 \mathrm{~mol} \%$, respectively, are within the range noted above for group I; however, selected characteristics easily differentiated them from $L$. jugurti (37.1 mol\%), $L$. helveticus $(38.3 \mathrm{~mol} \%)$, L. salivarius $(32.4$ $\mathrm{mol} \%$ ), and $L$. acidophilus ( $36.7 \mathrm{~mol} \%$ ).

Although the malty strains produced an extracellular nuclease capable of hydrolyzing RNA and DNA, this particular characteristic was not useful for species differentiation because several homo- and heterofermentative lactobacilli exhibit extracellular nucleolytic activity (21).

The ability to grow at $15 \mathrm{C}$ is a useful criterion for preliminary classification of lactobacilli. Although strains of thermobacteria do not grow at this temperature, all streptobacteria are capable of growth at $15 \mathrm{C}$ and usually even at 6 to $7 \mathrm{C}$. In addition to the latter characteristic, the data obtained concerning glucose and gluconate utilization, ribose fermentation, fructose-1,6-diphosphate aldolase activity, growth factor requirements, and the type of lactic acid produced substantiate the placement of the malty isolates in the subgenus Streptobacterium (31). At present, this subge- nus contains only two species, $L$. plantarum and $L$. casei, with subspecies $L$. casei subsp. rhamnosus and $L$. casei subsp. alactosus. $L$. plantarum produces a small amount of acid in milk, whereas $L$. casei produces 1.2 to $1.5 \%$. The latter species also produces $\mathrm{L}(+)$-lactic acid, whereas $L$. plantarum forms DL-lactic acid, actively ferments melibiose, and is capable of growth in the presence of $0.4 \%$ Teepol. With few exceptions, the characteristics reported for strains MX5R, MX5S, 674S, and 628S did not correlate exactly with those for known strains of either L. casei or L. plantarum.

Although $L$. casei and L. plantarum are the only recognized species in the subgenus Streptobacterium, several low-temperature, homofermentative strains have been reported as unclassified streptobacteria. Keddie (11) described atypical strains that were less active in fermentation tests than either $L$. casei or $L$. plantarum, and additional intermediate strains have been reported by Perry and Sharpe (30) and Naylor and Sharpe (25-27). Since the malty isolates characterized in this study differed in some traits from the known species and subspecies contained in the subgenus Streptobacterium, they appear to represent intermediate strains or a new species of the subgenus Streptobacterium.

The mean DNA base compositions calculated from data previously reported for $L$. case $i$ and L. plantarum ranged from 43.1 to $47.3 \mathrm{~mol} \%$ GC $(6,22)$. A difference in GC content of 10.1 to $11.3 \mathrm{~mol} \%$ for $L$. case $i$ and 7.1 to $9.0 \mathrm{~mol} \%$ for $L$. plantarum is evident when compared with the mean value, $36 \mathrm{~mol} \% \mathrm{GC}$, obtained for 

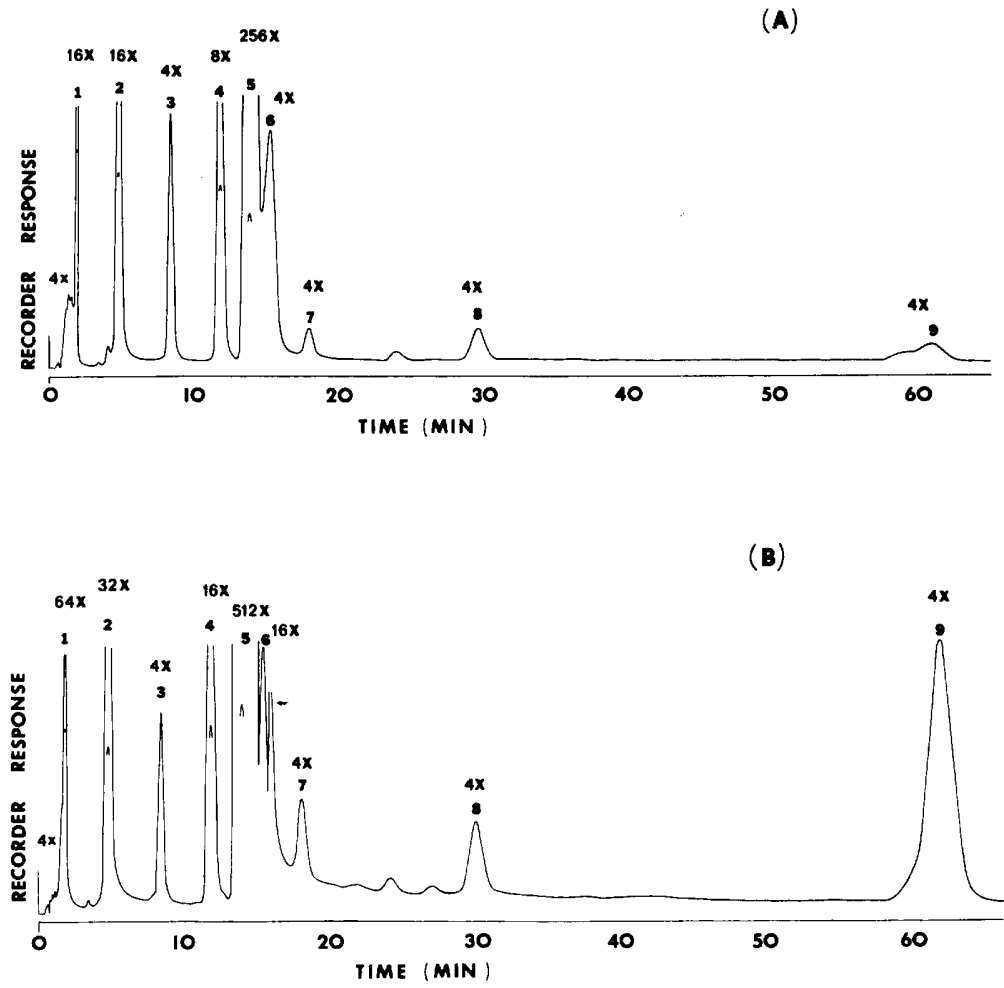

FIG. 4. Volatile compounds produced in (A) skim milk and (B) TSB by malty strain 674R. Compounds identified are: 1, diethyl ether; 2, acetaldehyde; 3, 2-methylpropanal; 4, acetone; 5, ethanol; 6, 3-methylbutanal; 7, butanone; 8, 2-methylpropanol; and 9, 3-methylbutanol. Column: 1, 2, 3-tris(2-cyanoethoxy)propane (3.7 m by $3 \mathrm{~mm}$ outer diameter).

the malty lactobacilli. Since the malty isolates and strains of $L$. case $i$ and $L$. plantarum have substantially different mean DNA base compositions, one can assume that they will have few DNA molecules or base sequences in common.

Like $S$. lactis subsp. maltigenes, the malty lactobacilli produce 2-methylpropanal, 2-methylpropanol, 3-methylbutanal, and 3-methylbutanol. The characteristic aroma of cultures of these organisms is most likely due principally to the production of the above aldehydes formed by mechanisms which may be similar to those reported for $S$. lactis subsp. maltigenes $(14,15$, 39).

We believe that the evidence presented herein justifies the recognition of the malty isolates, strains MX5R, MX5S, 674S, and $628 \mathrm{~S}$, as belonging to a new species, for which we propose the name Lactobacillus maltaromicus (malt.a.ro'mi.cus. M.E. noun malte ground dried sprouted barley; L. noun aroma pleasant odor; M.L. adj. maltaromicus possessing a maltlike aroma).
A description of the type strain, MX5 (ATCC 27865), follows:

Cells: Thin rods which vary in length and occur mostly in chains or long filaments; they are gram positive, becoming gram negative with age, and are nonmotile.

Agar colonies: White, convex, smooth, entirely to slightly fimbriate, opalescent. Some cultures produce coarsely fimbriate colonies with a coarse ground-glass appearance.

Broth: Flocculate, clearing after a few days.

Milk: Maximum acidity produced is $0.4 \%$ in 14 days.

Acid is produced from ribose, glucose, fructose, galactose, mannose, maltose, lactose, sucrose, cellibiose, melizitose, trehalose, melibiose, mannitol, sorbitol, $\alpha$-methyl-D-glucoside, $\alpha$-methyl-D-glucoside, $\alpha$-methyl-D-mannoside, salicin and amygdalin. Raffinose, xylose, arabinose, rhamnose, erythritol, adonitol, dulcitol, and inositol are not fermented.

$\mathrm{L}(+)$-lactic acid is the major product of glucose fermentation; carbon dioxide is not produced. 
A limited amount of carbon dioxide is produced from gluconate.

Catalase is not produced.

Nitrite is not produced from nitrate.

Growth factor requirements: Riboflavin and folic acid are essential; thiamine is not required. Microaerophilic.

Temperature relations: Optimum, between 25 and 32 C. Minimum, 7 C. Maximum, between 37 and $40 \mathrm{C}$.

DNA: $T_{m}, 84.0$. GC content, $36.0 \mathrm{~mol} \%$.

Distinctive character: This organism produces 2-methylpropanal and 3-methylbutanal and the corresponding alcohols in milk and other media. The aldehydes are most likely responsible for the malt-like aroma of such cultures.

Source: Isolated from milk.

\section{ACKNOWLEDGMENTS}

We are grateful to E. O. Anderson, deceased, formerly of the Connecticut Department of Agriculture and Natural Resources, for providing the producer milk samples from which the organisms described herein were isolated. We also wish to express our appreciation to C. Daly and C. Speckman, Department of Microbiology, for their assistance in determining the optical rotation of lactic acid.

\section{LITERATURE CITED}

1. Baumann, J. 1934. Cited in A. I. Ventanem and O. E. Nikkla. 1947. "Malty flavor" in starter and butter. J. Dairy Res. 15:89 (1947).

2. Daly, C., W. E. Sandine, and P. R. Elliker. 1972. Interactions of food starter cultures and foodborne pathogens: Streptococcus diacetilactis versus food pathogens. J. Milk Food Technol. 35:349-357.

3. DeMan, J. C., M. Rogosa, and M. E. Sharpe. 1960. A medium for the cultivation of lactobacilli. J. Appl. Bacteriol. 23:130-135.

4. Difco Laboratories. 1953. Difco manual of dehydrated culture media and reagents for microbiological and clinical laboratory procedures. 9 th ed. Dif co Laboratories, Detroit, Mich.

5. Feagan, J. 1958. Isolation of a malt flavor producing strain of Streptococcus faecalis. Aust. J. Dairy Technol. 13:79.

6. Gasser, F., and M. Mandel. 1968. Deoxyribonucleic acid base composition of the genus Lactobacillus. J. Bacteriol. 96:580-588.

7. Gordon, D. F., M. E. Morgan, and J. S. Tucker. 1963. Differentiation of Streptoccus lactis var. maltigenes from other lactic streptococci. Appl. Microbiol. 11:171-177.

8. Hammer, B. W., and W. A. Cordes. 1921. Burnt or caramel flavor of dairy products. Iowa Agr. Exp. Sta. Res. Bull. 68:146.

9. Hansen, P. A. (secretary). 1968. Type strains of Lactobacillus species. (A report by the taxonomic subcommittee on lactobacilli and closely related organisms of the International Committee on Nomenclature of Bacteria of the International Association of Microbiological Societies). American Type Culture Collection, Rockville, Md.

10. Jeffries, C. D., D. F. Holtman, and D. G. Guse. 1957. Rapid method for determining the activity of microorganisms on nucleic acids. J. Bacteriol. 73:590-591.

11. Keddie, R. M. 1959. The properties and classification of lactobacilli isolated from grass and silage. J. Appl. Bacteriol. 22:402-416.

12. Knittel, M. D., C. H. Black, W. E. Sandine, and D. K. Fraser. 1968. Use of normal probability paper in determining thermal melting values of deoxyribonucleic acid. Can. J. Microbiol. 14:239-245.

13. Leesmont, H. 1962. Bacteria in starters producing a malty flavor. 16th International Dairy Congress, Section III, 2:209-216. Copenhagen, Denmark.

14. MacLeod, H. P., and M. E. Morgan. 1956. Leucine metabolism of Streptococcus lactis var. maltigenes. II. Transaminase and decarboxylase activity of acetone powders. J. Dairy Sci. 39:1125-1133.

15. MacLeod, H. P., and M. E. Morgan. 1958. Differences in the ability of lactic streptococci to form aldehydes from certain amino acids. J. Dairy Sci. 41:908-913.

16. Marmur, J. 1961. A procedure for the isolation of deoxyribonucleic acid from microorganisms. J. Mol. Biol. 3:208-218.

17. Marmur, J., and P. Doty. 1962. Determination of the base composition of deoxyribonucleic acid from its thermal denaturation temperature. J. Mol. Biol. 5:109-118.

18. Mattsson, S. 1965. The determination of the configuration of lactic acid in bacterial cultures. Milk Dairy Res. 71:5-15.

19. McDonnell, M. E. 1899. Cited in B. W. Hammer and W. A. Cordes. 1921. Burnt or caramel flavor of dairy products. Iowa Agr. Exp. Sta. Res. Bull. 68:146.

20. Miller, A., III, and M. E. Morgan. 1968. Genetic homology and attempted transformation among certain lactic streptococci. J. Dairy Sci. 51:1-7.

21. Miller, A., III, W. E. Sandine, and P. R. Elliker. 1971. Extracellular nuclease in the genus Lactobacillus. J. Bacteriol. 108:604-606.

22. Miller, A., III, W. E. Sandine, and P. R. Elliker. 1971. Deoxyribonucleic acid base composition of lactobacilli determined by thermal denaturation. J. Bacteriol. 102:278-280.

23. Morgan, M. E., and E. A. Day. 1965. Simple on-column trapping procedure for gas chromatographic analysis of flavor volatiles. J. Dairy Sci. 48:1382-1384.

24. Morgan, M. E., R. C. Lindsay, L. M. Libbey, and R. L. Pereira. 1966. Identity of additional aroma constituents in milk cultures of Streptococcus lactis var. maltigenes. J. Dairy Sci. 49:15-18.

25. Naylor, J., and M. E. Sharpe. 1958. Lactobacilli in cheddar cheese. I. The use of selective media for isolation and of serological typing for identification. J. Dairy Res. 25:92-103. 
26. Naylor, J., and M. E. Sharpe. 1958. Lactobacilli in cheddar cheese. II. Duplicate cheese. J. Dairy Res. 25:421-430.

27. Naylor, J., and M. E. Sharpe. 1958. Lactobacilli in cheddar cheese. III. The source of lactobacilli in cheese. J. Dairy Res. 25:431-438.

28. Orla-Jensen, S. 1919. The lactic acid bacteria. Andr. Fred. Host and Son, Copenhagen.

29. Overby, A. J. 1957. Maltsmag i syrevaekkere og smor. Maelkeritidende 70:675-679.

30. Perry, K. D., and M. E. Sharpe. 1960. Lactobacilli in raw milk and in cheddar cheese. J. Dairy Res. 27:267-275.

31. Rogosa, M. 1970. Characters used in the classification of lactobacilli. Int. J. Syst. Bacteriol. 20:519-533.

32. Rogosa, M., and M. E. Sharpe. 1959. An approach to the classification of lactobacilli. J. Appl. Bacteriol. 22:329-340。

33. Rogosa, M., R. F. Wiseman, J. A. Mitchell, M. N. Disraely, and A. J. Beaman. 1953, Species differentiation of oral lactobacilli from man including descriptions of Lactobacillus salivarius nov. spec. and Lactobacillus cellobiosus nov. spec. J. Bacteriol. 65:681-699.

34. Sadler, W. 1911. A note on an organism producing a burnt milk taste. Zentralbl. Bakteriol. Abt. 2. 29:1.

35. Sadler, W. 1926. The production of a "caramel" odor and flavor in dairy products by Streptococcus lactis (Lister). Proc. Trans, Roy, Soc. Canada Ser. 3 20:395.

36. Sheldon, R. M., R. C. Lindsay, L. M. Libbey, and M. E. Morgan. 1971. Chemical nature of malty flavor and aroma produced by Streptococcus lactis var. maltigenes. Appl. Microbiol. 22:263-266.

37. Society of American Bacteriologists. 1957. Manual of microbiological methods. McGraw-Hill Book Co., New York.

38. Tracy, P. H., and R. J. Ramsey. 1931. Malt flavor in raw milk produced by micrococcus. J. Dairy Sci. 14:457-462.

39. Tucker, J. S., and M. E. Morgan。1967. Decarboxylation of alpha-keto acids by Streptococcus lactis var. maltigenes. Appl. Microbiol. 15:694-700. 